
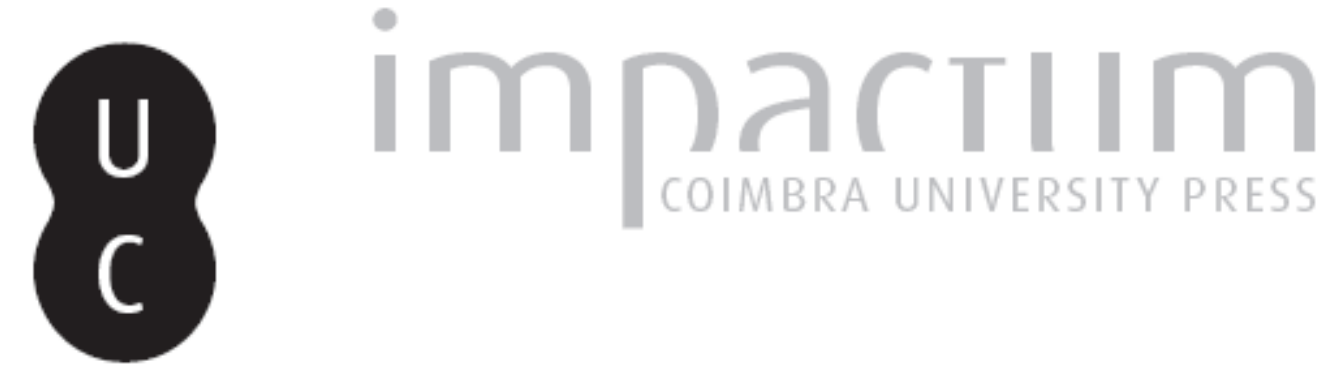

\title{
[Recensão a] Environmental Law and Consumer Protection European Journal of Consumer Law/Revue Européenne de Droit de la Consommation
}

\author{
Autor(es): $\quad$ Aragão, Maria Alexandra \\ Publicado por: CEDOUA \\ URL \\ persistente: \\ URI:http://hdl.handle.net/10316.2/40051 \\ DOI: \\ DOI:https://doi.org/10.14195/2182-2387_27_7
}

Accessed : $\quad$ 26-Apr-2023 12:09:53

A navegação consulta e descarregamento dos títulos inseridos nas Bibliotecas Digitais UC Digitalis, UC Pombalina e UC Impactum, pressupõem a aceitação plena e sem reservas dos Termos e Condições de Uso destas Bibliotecas Digitais, disponíveis em https://digitalis.uc.pt/pt-pt/termos.

Conforme exposto nos referidos Termos e Condições de Uso, o descarregamento de títulos de acesso restrito requer uma licença válida de autorização devendo o utilizador aceder ao(s) documento(s) a partir de um endereço de IP da instituição detentora da supramencionada licença.

Ao utilizador é apenas permitido o descarregamento para uso pessoal, pelo que o emprego do(s) título(s) descarregado(s) para outro fim, designadamente comercial, carece de autorização do respetivo autor ou editor da obra.

Na medida em que todas as obras da UC Digitalis se encontram protegidas pelo Código do Direito de Autor e Direitos Conexos e demais legislação aplicável, toda a cópia, parcial ou total, deste documento, nos casos em que é legalmente admitida, deverá conter ou fazer-se acompanhar por este aviso.

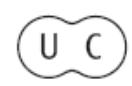



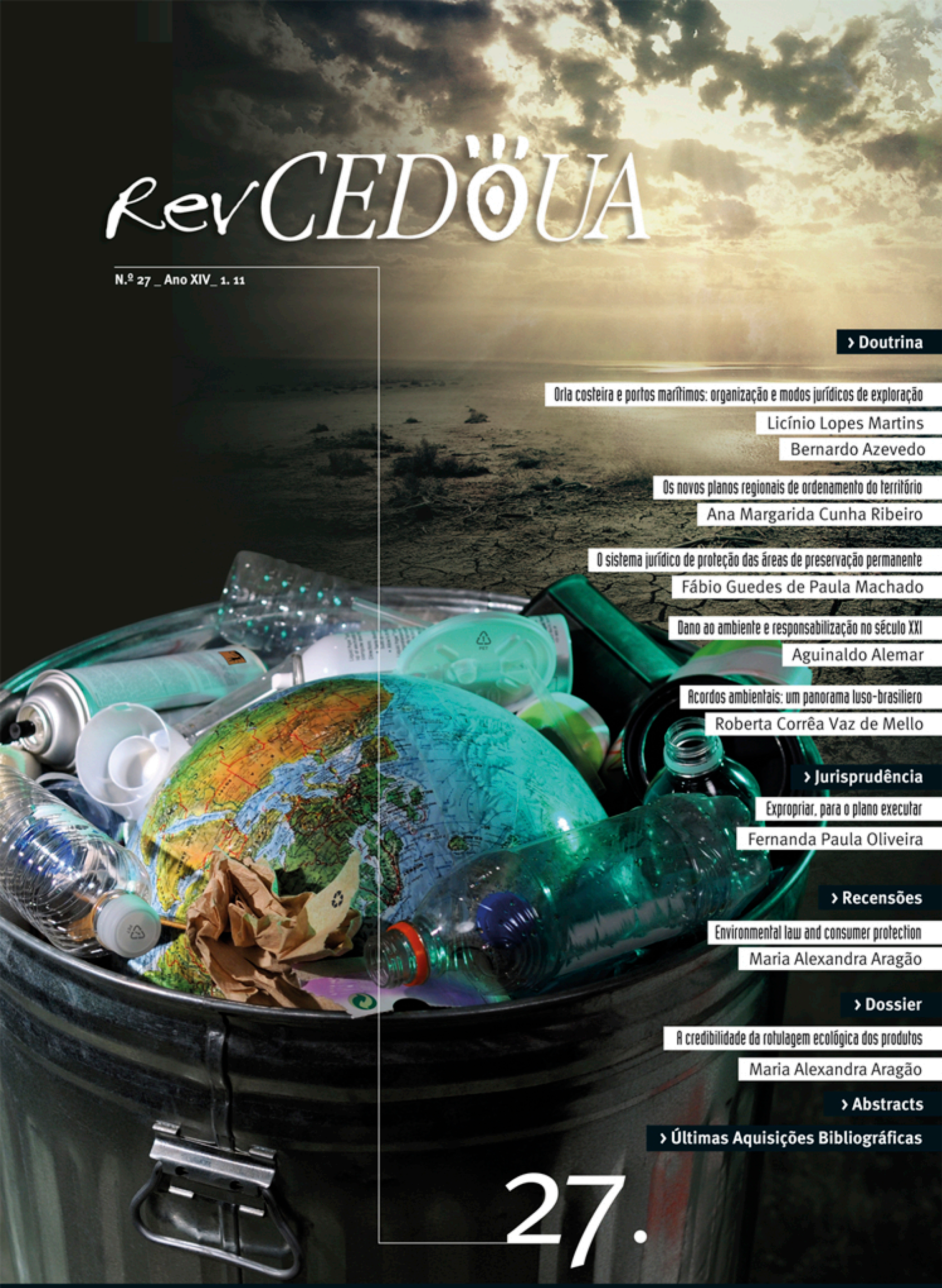

Revista do Centro de Estudos de Direito do Ordenamento, do Urbanismo e do Ambiente Urbanism, Territorial Order and Environment Studies Center Law Review 


\section{Environmental Law and Consumer Protection European Journal of Consumer Law/Revue Européenne de Droit de la Consommation, n.11/1, Bruxelas, 2011. Christophe Verdure (editor)}

Num número especial da revista europeia de Direito do Consumo (European Journal of Consumer Law/Revue Européenne de Droit de la Consommation), dedicado ao tema do ambiente, a relação entre o Direito Ambiental e a protecção dos consumidores é o tópico central que, pela sua enorme actualidade, há muito que merecia uma edição monográfica.

A revista é uma publicação bilingue que no seu primeiro número de 2011, intitulado Environmental Law and Consumer Protection optou por publicar todos os artigos em inglês, mesmo no caso de autores francófonos.

A obra pretende reflectir as novas aproximações de baixo para cima ("bottom up"), à protecção do ambiente, em que as preocupações ambientais são perspectivadas como responsabilidade de todos, em conformidade com o Sexto Programa de Acção da União Europeia em matéria ambiental (Decisão n. ${ }^{\circ} 1600 / 2002$, de 22 de Julho), justamente intitulado "o nosso futuro, a nossa escolha".

O volume organizado por Christophe Verdure, está dividido em três partes:

1. A relação entre os consumidores e o ambiente, abordando temas como o consumo sustentável, a relação do direito ambiental com os direitos humanos e o papel activo dos consumidores, através da Convenção de Aarhus.

2. A protecção dos consumidores pela regulação ambiental, a partir de casos de estudo em três áreas: nanotecnologias, água e clima.

3. Regimes de responsabilidade ambiental e protecção do consumidor, onde às perspectivas civil e criminal acresce um estudo específico sobre poluição gerada em navios.

No primeiro artigo sobre consumo sustentável, Klaus Tonner realça o papel dos consumidores na protecção ambiental.

O documento chave em matéria de consumo sustentável é o capítulo 4 da Agenda 21, que desenvolve novos conceitos de riqueza e prosperidade, com melhor qualidade de vida e menos dependência dos recursos finitos da Terra. Assim é possível distinguir um consumo sustentável mais "mole" (soft), orientado para a eficiência, de outro considerado "duro" (hard), mais orientado para mudanças no estilo de vida. 


\section{$\operatorname{RerCEDöUA~}$}

$>$ Recensão

Para o efeito, é fundamental a informação, tanto sobre os impactes ambientais do consumo, como sobre o funcionamento de projectos vocacionados para os consumidores, como os sistemas de reciclagem ou de consignação e depósito de embalagens. Cientes dos impactes e das oportunidades, é mais provável que os consumidores façam escolhas mais sustentáveis. Considerando que os preços de mercado não reflectem bem a escassez futura dos recursos naturais, os incentivos através dos preços são também fundamentais. Nas palavras do autor, o mercado é "cego quanto ao futuro", até porque as próprias gerações futuras não são "actores no mercado".

A encerrar, Tonner analisa o transporte e o turismo como sectores onde a contribuição dos consumidores para a redução de certas formas de poluição, consumos energéticos e emissões de $\mathrm{CO} 2$ é determinante.

Em seguida, o tema dos direitos fundamentais e a protecção do ambiente no direito europeu e na Convenção Europeia dos Direitos Humanos é objecto de análise por Nicolas de Sadeleer, num capítulo com três partes principais: a protecção do ambiente nos Tratados e na Carta dos Direitos Fundamentais da União, o direito subjectivo à protecção do ambiente, no direito europeu derivado, e o contributo da Convenção Europeia dos Direitos do Homem para a protecção ambiental.

Após análise do direito primário e secundário europeu, dando especial destaque aos direitos de acesso à informação e participação, Sadeleer conclui que a União Europeia entrou numa nova etapa de democratização de uma política que originalmente se caracterizava por ter um cunho muito técnico.

Relativamente aos contributos ambientais da Convenção Europeia dos Direitos do Homem, Nicolas de Sadeleer chama a atenção para o facto de (apesar da ausência de um direito autónomo à protecção ambiental, e apesar de o Tribunal afirmar não reconhecer um estatuto especial aos "direitos ambientais fundamentais"), existirem já um número significativo de decisões judiciais com relevância ambiental. Essas decisões são baseadas em cinco artigos da Convenção (o artigo $2^{\circ}$, sobre o direito à vida, 0 artigo 6으 sobre o direito a um processo equitativo, 0 artigo $8^{\circ}$ sobre o direito à vida privada, ao domicílio e à informação, o artigo $10^{\circ}$ - sobre direito à informação e o artigo $11^{\circ}$ sobre liberdade de reunião e associação), e ainda um artigo do Protocolo anexo à Convenção(o artigo $1^{\circ}$, sobre direito de propriedade).

Em conclusão, o sistema de protecção instituído pela Convenção é criticado pela sua insuficiência, na medida em que o reconhecimento da violação de um direito humano exige a prova de uma violação grave, ao passo que, para a prova da violação do mesmo direito no contencioso civil ou administrativo, bastaria alegar e provar a ultrapassagem dos valores- limite estabelecidos na lei ou na licença, ou a falta de autorização prévia.

No capítulo seguinte, é Ester Pozo Vera que dedica atenção à Convenção de Aarhus, procedendo a uma exposição sistemática do seu conteúdo, com base nos conhecidos três pilares em torno dos quais ela se estrutura: acesso à informação, participação e acesso à justiça.

O carácter inovador da Convenção decorre, antes de mais, do reconhecimento de um direito fundamental ao ambiente, bem como da consagração da ideia de equidade intergeracional, associado a poderosos mecanismo do controlo, pela sociedade civil, do cumprimento das responsabilidades ambientais impostas.

No primeiro pilar, o acesso activo e passivo à informação são pormenorizadamente descritos quanto ao seu conteúdo e condições.

Relativamente ao segundo pilar, as diferentes oportunidades de participação e os deveres públicos dela decorrentes, são explanados, tendo em consideração a jurisprudência do Comité de Cumprimento.

Por fim, no acesso à justiça, enquanto terceiro pilar da Convenção, Ester Pozo Vera confronta a teoria e a prática dos Estados. 
De forma animadora, a autora conclui que Aarhus é um instrumento central na promoção da democracia ambiental, transformando os cidadãos e os consumidores em jogadores activos da luta contra a corrupção, nomeadamente ao nível do planeamento urbano e do desenvolvimento industrial.

A emergência das nanotecnologias e a protecção dos consumidores é o tema central do capítulo da autoria de Geert van Calsen, Diana M. Bowman e Joel D'Silva. O primeiro foco dos autores é a indústria cosmética, como um dos principais sectores de aplicação de nanotecnologias, e também um dos que levanta especiais preocupações pela forma de utilização: a aplicação de cosméticos é feita por via tópica, podendo os produtos de embelezamento conter nanopartículas insolúveis ou persistentes, ou nanopartículas biodegradáveis, cujos efeitos sobre a saúde humana ainda são incertos.

Analisam em seguida a produção e colocação no mercado de alimentos na União Europeia, onde a segurança dos alimentos está dependente de uma monitorização e reavaliação permanente em virtude de novas informações científicas.

Mas os avanços das nanotecnologias no que respeita aos usos médicos, são os que envolvem um maior potencial de risco para a saúde. Desde os nanomedicamentos, aos nanossistemas de diagnóstico, passando por nanoterapias, está a nascer um mundo de novos avanços na medicina mas, ao mesmo tempo, um mundo de novos riscos para a saúde e o ambiente.

$\mathrm{Na}$ União Europeia, a falta de dados científicos sobre os efeitos das nanotecnologias não justificou uma resposta porvia de regulação proibitiva, mas antes a introdução daquilo que os autores chamam "nano ganchos" na legislação.

No capítulo seguinte, Marleen van Rijswick debruça-se sobre o estatuto dos consumidores na legislação europeia sobre a água. Chamando a atenção para o facto de a água não ser, à luz do direito europeu, "um produto comercial como qualquer outro", mas antes "um património, que deve ser protegido”, mostra como o estatuto jurídico da água (bem privado, bem público, regime fiscal e de preços, etc.) varia muito de Estado para Estado.

A autora identifica os aspectos substantivos e processuais da protecção dos consumidores, no Direito europeu da água. Como aspectos substanciais, a protecção da qualidade da água, o acesso à água e aos serviços da água, um uso sustentável e equitativo da escassa água potável, protecção contra inundações, protecção dos ecossistemas e um preço justo pelos serviços hídricos. Do lado dos aspectos processuais realça o acesso à informação ambiental relevante, a transparência, a participação na tomada de decisões, a responsabilização (accountability) e o acesso à justiça.

Cada um destes aspectos é sistematicamente examinado quanto à sua consagração nas várias directivas europeias relativas à água desde a directiva quadro, à directiva sobre águas de consumo, a directiva sobre tratamento de águas residuais, a directiva sobre abastecimento de água potável, a directiva sobre inundações e a directiva sobre água balnear. No final, três quadros comparativos sintetizam a protecção dos consumidores pelo direito europeu da água, permitindo concluir que, embora os consumidores estejam relativamente bem protegidos nos seus direitos relativos à água, ainda poderiam estar mais.

Os consumidores e o direito do clima é o desafio que levou Javier Cendra Larragán a analisar as emissões relacionadas com o consumo. A principal questão a ser colocada foi a forma como a União Europeia lida com as decisões dos consumidores com impactes sobre o clima. Após a descrição do surgimento da temática das alterações climáticas tanto no direito primário como no direito secundário europeu, Javier Cendra Larragán analisa as medidas adoptadas na União Europeia, consoante sejam medidas orientadas para o lado da oferta ou para o lado da procura. Esta últimas são as medidas que orientam os comportamentos 


\section{$\operatorname{RerCEDöUA~}$}

$>$ Recensão

dos consumidores melhorando a informação sobre o consumo energético dos produtos ou regulando as características energéticas dos próprios produtos. 0 autor considera que estas medidas não são suficientes para mudar os comportamentos dos consumidores e que faltam medidas que regulem directamente esses comportamentos.

Uma solução para promover o consumo doméstico sustentável, passa por uma grande mudança no panorama regulatório, através da criação de licenças transaccionáveis pessoais.

A concluir, a parte III da obra é dedicada ao estudo da responsabilidade ambiental na União Europeia, começando pelo estudo principial da Directiva sobre responsabilidade ambiental administrativa, na análise de Sandra Cassotta. Segue-se uma perspectiva crítica sobre a Directiva relativa à criminalidade ambiental (analisada por Michael G. Faure) e, por fim, as sanções criminais para a poluição gerada por navios, onde Gwendoline Gonsaeles faz o levantamento dos regimes de Direito Internacional e Europeu, ao nível legislativo e jurisprudencial.

Maria Alexandra Aragão Professora da Faculdade de Direito da Universidade de Coimbra 